\title{
Sistem Monitoring Suhu dan Kelembaban pada Inkubator Bayi Berbasis Mikrokontroler
}

\author{
Heri Mulyono ${ }^{1}$, Yuan Novandhya Yudistira ${ }^{2}$ \\ ${ }^{1,2}$ Program Studi Sistem Komputer STMIK Jayanusa Padang \\ herimulyonoaja@gmail.com, yuan.novan@gmail.com
}

\begin{abstract}
Abstrak
Telah dilaksanakan penelitian tentang pembuatan sistem monitoring suhu dan kelembaban pada ruang inkubator bayi berbasis mikrokontroler. Sistem yang dibangun terdiri dari tiga bagian, yaitu input, proses dan output. Komponen input menggunakan dua jenis sensor yaitu sensor suhu dan sensor kelembaban. Komponen proses menggunakan mikrokontroler Atmega, dan komponen Output menggunakan lampu pijar sebagai pemanas, kipas angin/ fan sebagai pendingin ruang inkubator bayi dan alarm sebagai indikator jika terjadi kesalahan atau kerusakan sistem. Metodologi yang digunakan dalam penelitian ini adalah berupa disain/ perancangan sistem yang melibatkan aspek perangkat keras dan perangkat lunak. Hasil penelitian ini berupa sebuah sistem elektronik yang dapat mendeteksi suhu dan kelembaban pada Inkubator bayi. Pada sistem ini mampu mempertahankan suhu yang dibutuhkan oleh bayi yaitu berkisar antara $32{ }^{\circ} \mathrm{C}$ sampai $37{ }^{\circ} \mathrm{C}$. Suhu dan kelembaban di dalam ruang inkubator dapat distabilkan menggunakan unsur pemanas dan pendingin yang dikendalikan lewat program komputer.
\end{abstract}

Kata kunci : Sistem, Inkubator, Mikrokontroler

\section{PENDAHULUAN}

Perawatan bayi pasca persalinan merupakan hal sangat penting untuk diperhatikan. Bayi yang baru lahir mempunyai tingkat sensitivitas yang tinggi terhadap perubahan lingkungan, apalagi dengan suhu udara di sekitarnya. Bayi yang baru lahir dianjurkan untuk segera dibersihkan sampai bersih kemudian diselimuti sampai hangat sebelum dimandikan atau ditimbang. Perawatan bayi baru lahir dalam hal menjaga kehangatan tubuh bayi dianjurkan menggunakan kanguru, yaitu bayi dalam pelukan sang ibu, kulit bayi menempel pada kulit ibu layaknya hewan kanguru. Tetapi tidak setiap kondisi sang ibu dapat menerapkan metode atau cara ini. Hal ini disebabkan kemungkinan kondisi sang ibu tidak sadarkan diri atau masih terbaring lemas akibat penyakit tertentu atau akibat operasi. Alat atau tempat yang biasa digunakan untuk merawat bayi secara intensif biasa disebut dengan Inkubator.

Inkubator pabrikan harganya relative mahal, dengan alasan ini, maka peneliti akan membuat sistem yang mirip dengan Inkubator. Pada prinsipnya bahwa Inkubator merupakan suatu tempat yang dapat menjaga kondisi suhu tetap stabil dan berdasarkan data bahwa bayi 
yang baru lahir suhu tubuhnya berkisar antara $32{ }^{\circ} \mathrm{C}$ sampai $37{ }^{\circ} \mathrm{C}$. Dengan range tersebut maka dibutuhkan suatu sistem pengendalian untuk memonitoring kondisi suhu pada Inkubator bayi tersebut

\section{A. Kajian Teori}

\section{Inkubator Bayi}

Inkubator bayi adalah alat yang digunakan untuk mempertahankan kondisi lingkungan yang cocok untuk bayi yang baru lahir, terutama bayi yang lahir secara prematur. Inkubator bayi merupakan salah satu metode dan sarana yang berfungsi untuk menunjang keadaan bayi yang baru lahir, sehingga diharapkan setiap intansi kesehatan yang berhubungan dengan proses persalinan ibu hamil dapat memiliki incubator bayi.

Inkubator bayi dikelompokkan menjadi 2 jenis yaitu Inkubator sederhana dan Inkubator digital.

a. Inkubator Sederhana

Inkubator yang banyak digunakan oleh instansi kesehatan kelas menengah ke bawah. Jenis ini biasanya berupa kotak (box bayi) yang dilengkapi dengan penghangat dan alat pengukur suhu ruang. Hal ini kurang efektif karena tidak ada pengatur suhu ruang incubator, sehingga panas ruang inkubator tidak dapat disesuaikan dengan kebutuhan bayi. b. Inkubator Digital

Inkubator bayi digital merupakan pengembangan dari inkubator bayi sederhana. Jenis ini ditambahkan fungsi yang berkaitan dengan pengaturan suhu ruang inkubator, kelembaban dan fasilitas keamanan jika terjadi error pada inkubator dilengkapi dengan alarm.

Secara umum Inkubator bayi yang akan dirancang terdiri dari bagian yaitu pemanas dan tempat penghangat bayi.

a. Pemanas

Pemanas adalah alat yang digunakan untuk mengubah besaran listrik menjadi besaran kalor (panas).

b. Tempat Penghangat Bayi

Tempat penghangat bayi (kotak incubator) dibuat seperti aquarium yang bagian atasnya tertutup dengan bahan acrylic, dan kerangka kotak menggunakan bahan aluminium. Sedangkan rangkaiannya diletakkan di bawah dari kotak inkubator.

Hal-hal yang perlu diperhatikan pada kotak Inkubator adalah suhu, kelembaban, sirkulasi udara dan penyebaran panas.

a. Temperatur dan Kelembaban Kelembaban udara ada 2 macam, yaitu: kelembaban absolute dan relative.

1. Kelembaban Udara Absolut Kelembaban udara absolute adalah banyaknya uap air yang 
ada di udara pada suatu tempat/ bejana tertentu. Dinyatakan dengan banyaknya (gram) uap air dalam satu meter kubik.

2. Kelembaban Udara Relatif

Kelembaban udara relative adalah perbandingan jumlah uap air dalam udara dengan kapasitas udara untuk menampung uap air dalam suhu yang sama dan dinyatakan dengan satuan persen (\%).

b. Sirkulasi udara

Kotak Inkubator yang dibuat harus mempunyai saluran sirkulasi udara yang merata pada setiap sisi, sehingga penyebaran panas dari ruang pemanas menuju kotak Inkubator dapat merata.

\section{Mikrokontroler Atmega 8535}

Mikrokontroller Atmega 8535 telah menggunakan konsep arsitektur Harvard yang memisahkan memori dan bus untuk data dan program, serta telah menerapkan single level pipelining. Arsitektur dari mikrokontroller AVR dapat dilihat pada gambar 2.1 sebagai berikut.

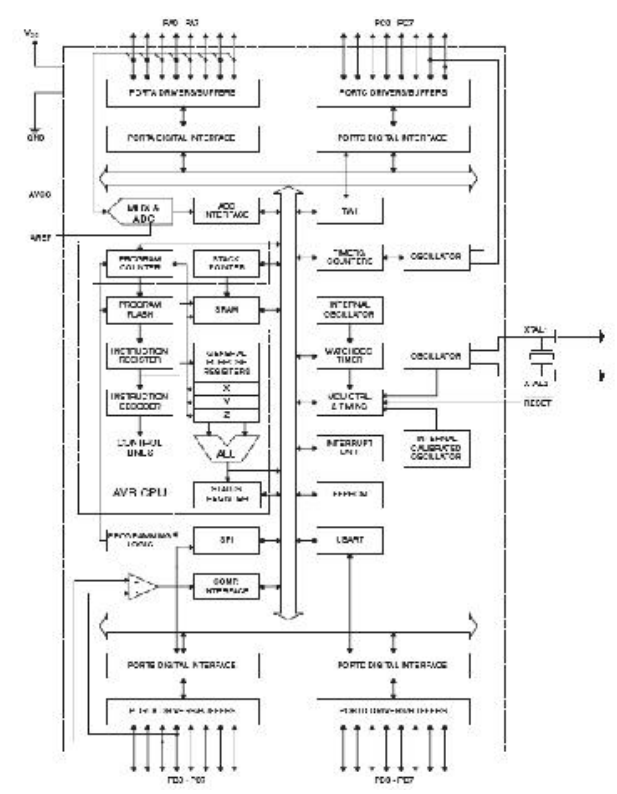

Gambar 2.1 Arsitektur

\section{Mikrokontroler ATMega 8535}

Berdasarkan gambar 2.1 tersebut, dapat dijelaskan bahwa Mikrokontroller ATmega8535 telah banyak digunakan untuk sistem yang kompleks, memiliki input sinyal analog, dan membutuhkan memori yang relatif lebih besar. Adapun skema pin dari Atmega 8535 adalah seperti terlihat pada gambar 2.2 berikut:

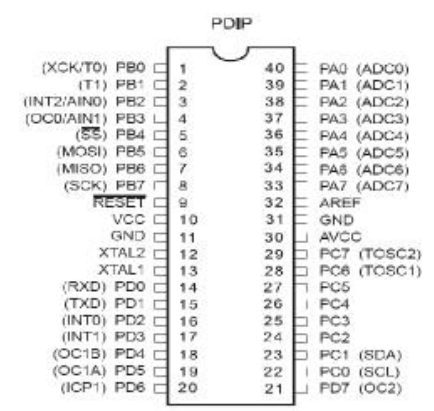

Gambar 2.2 Konfigurasi ATMega 8535

Berdasarkan gambar 2.2 di atas, bahwa secara fungsional konfigurasi pin ATMega8535 adalah sebagai berikut : 
1. Port A (PA0..PA7) merupakan pin I/O dua arah dan pin masukan ADC.

2. Port B (PB0..PB7) merupakan pin $\mathrm{I} / \mathrm{O}$ dua arah dan pin fungsi khusus, yaitu Timer/Counter, komparator analog, dan SPI.

3. Port $\mathrm{C}(\mathrm{PC} 0 . . \mathrm{PC} 7)$ merupakan pin $\mathrm{I} / \mathrm{O}$ dua arah dan pin fungsi khusus, yaitu TWI, komparator analog, dan Timer Oscilator.

4. Port D (PD0..PD7) merupakan pin I/O dua arah dan pin fungsi khusus, yaitu komparator analog, interupsi eksternal, dan komunikasi serial.

5. XTAL1 dan XTAL2 merupakan pin masukan clock eksternal.

\section{Sensor HSM20G}

Sensor HSM20G merupakan sensor pengukur kelembaban dan temperature, dan secara fisik dapat dilihat pada gambar 2.3 seperti berikut:
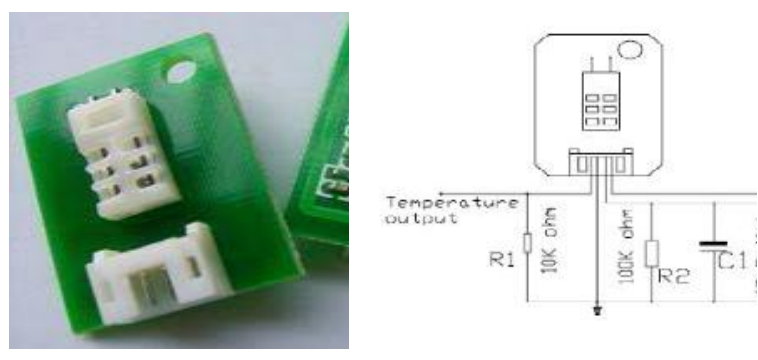

\section{Gambar 3.1 Sensor HSM20G dan rangkaian dasar sensor}

Adapun spesifikasi HSM20G adalah sebagai berikut:
- Beroperasi pada kelembaban antara $20 \%$ s/d 95\% RH

- Bekerja pada suhu $0 \mathrm{~s} / \mathrm{d} 50^{\circ} \mathrm{C}$

- Waktu respon 1 menit

\section{Sensor LM35}

Sensor LM35 adalah sensor suhu mampu mengukur suhu hingga $100^{\circ} \mathrm{C}$. Tegangan keluaran yang terskala linear dengan suhu terukur, yaitu $10 \mathrm{mV} / 1^{0} \mathrm{C}$. Berikut adalah rangkaian dasar sensor LM35:

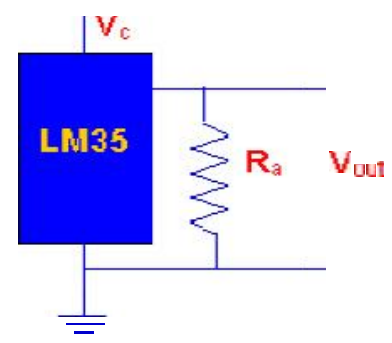

\section{Gambar 3.2 Sensor LM35}

\section{METODOLOGI PENELITIAN}

Metodologi yang digunakan pada penelitian ini adalah berupa disain sistem yang digambarkan dalam bentuk blok diagram seperti berikut ini:

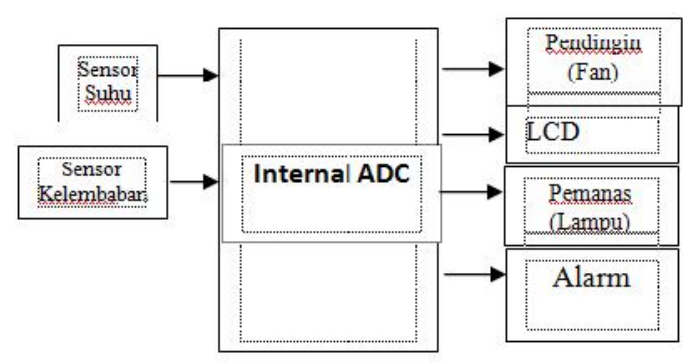

Gambar 3.3 Blok Diagram Sistem 
Berdasarkan gambar 3.1 di atas, dapat dijelaskan bahwa input dari sistem yang dibangun adalah sensor suhu dan sensor kelembaban, bagian pemroses adalah mikrokontroler Atmega 8535, dan bagian output dari sistem berupa tampilan angka, pemanas, pendingin dan Indikator alarm. Sensor suhu (LM35) akan mendeteksi suhu di dalam Inkubator bayi, sensor kelembaban (HSM20G) mendeteksi prosentase kelembaban di dalam Inkubator bayi. Tegangan keluaran sensor LM35 dan HSM20G berupa tegangan analog untuk itu perlu dikonversi menggunakan internal ADC mikrokontroler. Kemudian nilai konversi akan dibandingkan dengan nilai yang diatur melalui program komputer, dan ditampilkan dalam bentuk nilai suhu dan kelembaban melalui modul LCD.

Jika nilai suhu $<32{ }^{\circ} \mathrm{C}$ maka pemanas (lampu) akan hidPeneup dan pendingin (fan) mati, jika suhu $>37^{\circ} \mathrm{C}$ maka pendingin (fan) hidup dan pemanas (lampu) mati. Begitu juga dengan kelembaban, jika kelembaban $<20 \%$, maka lampu akan mati dan fan hidup. Jika kelembaban $>40 \%$, maka lampu akan hidup dan fan mati. Keterkaitan antara suhu, kelembaban, pemanas, pendingin, dan alarm dapat dirangkum seperti pada tabel berikut:

Tabel 1. Kondisi suhu, kelembaban, pemanas, pendingin dan alarm

\begin{tabular}{|l|l|l|l|l|}
\hline Suh & Kelemb & Pemanas & Pendin & Indikat \\
\hline
\end{tabular}

\begin{tabular}{|c|c|c|c|c|}
\hline $\begin{array}{c}\mathrm{u} \\
\left({ }^{\circ} \mathrm{C}\right)\end{array}$ & $\begin{array}{c}\text { aban } \\
(\%) \mathrm{RH}\end{array}$ & (Lampu) & $\begin{array}{c}\text { gin } \\
(\text { Fan })\end{array}$ & $\begin{array}{c}\text { or } \\
\text { (Alarm } \\
\text { ) }\end{array}$ \\
\hline $\begin{array}{l}32 \\
- \\
37\end{array}$ & $20-40$ & Mati & Mati & Mati \\
\hline $\begin{array}{l}< \\
32\end{array}$ & $20-40$ & Hidup & Mati & Mati \\
\hline $\begin{array}{c}> \\
37\end{array}$ & $20-40$ & Mati & Hidup & Mati \\
\hline $\begin{array}{c}32 \\
- \\
37\end{array}$ & $<20$ & Mati & Hidup & Hidup \\
\hline $\begin{array}{l}32 \\
- \\
37\end{array}$ & $>40$ & Hidup & Mati & Hidup \\
\hline $\begin{array}{l}< \\
32\end{array}$ & $<20$ & Hidup & Mati & Hidup \\
\hline $\begin{array}{l}> \\
37\end{array}$ & $>40$ & Mati & Hidup & Hidup \\
\hline
\end{tabular}

\section{HASIL PENELITIAN}

Hasil penelitian ini berupa prototype system monitoring Inkubator bayi yang dikendalikan oleh mikrokontroler.

\section{Hasil Pengujia Modul Power Supply}

Modul ini berfungsi memberikan supply tegangan pada semua rangkaian yang terhubung. Berikut adalah data hasil pengukuran: 
Penelitian Bidang Komputer Sains dan Pendidikan Informatika

Tabel 2. Data Pengukuran Tegangan Power Supply

\begin{tabular}{|c|cc|c|c|}
\hline No & \multicolumn{2}{|c|}{ Modul 12 V } & \multicolumn{2}{c|}{ Modul 5 V } \\
\hline & Tegangan & Deviasi & Tegangan & deviasi \\
\hline 1 & 11.92 & 0.0240 & 4.98 & 0.032 \\
\hline 2 & 11.94 & 0.0040 & 5.02 & 0.008 \\
\hline 3 & 11.94 & 0.0040 & 5.01 & 0.002 \\
\hline 4 & 11.96 & 0.0160 & 5.03 & 0.018 \\
\hline 5 & 11.96 & 0.0160 & 5.02 & 0.008 \\
\hline Jumlah & 11.944 & & 5.012 & \\
\hline & & 0.0240 & & 0.0320 \\
\hline Ketidak Pastian & $0.20 \%$ & \multicolumn{2}{|c|}{$0.64 \%$} \\
\hline Ketelitian & \multicolumn{2}{|c|}{$99.78 \%$} & \multicolumn{2}{|c|}{$99.36 \%$} \\
\hline
\end{tabular}

Berdasarkan table 4.1 dapat disimpulkan, bahwa:

1. Pada Modul $12 \mathrm{~V}$

Persentase ketidak pastian $=$

$(0.024 / 11.944) * 100 \%=0.20 \%$

Ketelitian $=100 \%-0.20 \%=99.78 \%$

2. Pada Modul 5 V

Persentase ketidak pastian $=$

$(0.0320 / 5.012) * 100 \%=0.64 \%$

Ketelitian $=100 \%-0.64 \%=99.36 \%$

Nilai ketelitian $99.78 \%$ dan $99.36 \%$ pada pengukuran, menunjukkan pengujian ini adalah valid.

\section{Pengujian Modul Sensor LM35}

Pengujian pada Sensor LM35 adalah mengukur tegangan keluaran pada saat modul dihidupkan dengan melakukan kalibrasi sensor dan pengaturan Set Point. Hasil pengukuran suhu dan tegangan dapat dirangkum dalam tabel 4.2.
Tabel 3 Data Hasil Pengujian Sensor Suhu LM35

\begin{tabular}{|c|c|c|}
\hline No & Suhu $\left({ }^{0} \mathrm{C}\right)$ & $\begin{array}{c}\text { Tegangan } \\
\text { Keluaran } \\
\text { (Volt) }\end{array}$ \\
\hline 1 & 25,49 & 0,254 \\
\hline 2 & 26,27 & 0,262 \\
\hline 3 & 27,45 & 0,274 \\
\hline 4 & 28,23 & 0,283 \\
\hline 5 & 29,41 & 0,294 \\
\hline 6 & 30,19 & 0,301 \\
\hline 7 & 31,37 & 0,313 \\
\hline 8 & 32,97 & 0,329 \\
\hline 9 & 33,72 & 0,336 \\
\hline 10 & 34,11 & 0,341 \\
\hline 11 & 35,29 & 0,353 \\
\hline 12 & 36,86 & 0,368 \\
\hline 13 & 37,64 & 0,376 \\
\hline 14 & 38,03 & 0,382 \\
\hline 15 & 40,00 & 0,400 \\
\hline 16 & 41,17 & 0,411 \\
\hline 17 & 42,35 & 0,423 \\
\hline 18 & 43,13 & 0,431 \\
\hline 19 & 44,31 & 0,443 \\
\hline 20 & 45,52 & 0,455 \\
\hline
\end{tabular}

Data maksimum suhu yang dapat ditampilkan di LCD adalah 100,0 dan tegangan keluaran analog maksumum $\left(\mathrm{V}_{1}\right.$ maks $)$ dari sensor suhu LM35 adalah 1 Volt. 
Penelitian Bidang Komputer Sains dan Pendidikan Informatika

3. Hasil Pengujian Sensor HSM20G

Tabel 4 Data Hasil Pengujian Sensor HSM20G

\begin{tabular}{|c|c|c|}
\hline No & $\begin{array}{c}\text { Kelembaban } \\
\text { dalam \% RH }\end{array}$ & $\begin{array}{c}\text { Teg. } \\
\text { Out } \\
\text { (Volt) }\end{array}$ \\
\hline 1 & 63,13 & 2,462 \\
\hline 2 & 63,92 & 2,475 \\
\hline 3 & 65,88 & 2,498 \\
\hline 4 & 67,05 & 2,567 \\
\hline 5 & 69,41 & 2,687 \\
\hline 6 & 70,98 & 2,691 \\
\hline 7 & 71,76 & 2,732 \\
\hline 8 & 72,15 & 2,740 \\
\hline 9 & 73,33 & 2,753 \\
\hline 10 & 75,29 & 2,772 \\
\hline 11 & 75,68 & 2,792 \\
\hline 12 & 77,64 & 2,802 \\
\hline 13 & 78,56 & 2,828 \\
\hline 14 & 81,56 & 2,875 \\
\hline 15 & 82,74 & 2,904 \\
\hline & & \\
\hline
\end{tabular}

Data maksimum kelembaban yang dapat ditampilkan di LCD adalah 100,0 tegangan keluaran analog maksumum ( $\mathrm{V}_{1}$ maks) dari sensor suhu HSM20G adalah sebesar 3,3 Volt.

\section{Hasil Pengujian Modul Rangkaian}

\section{Buzzer}

Rangkaian ini digunakan sebagai indicator jika terjadi perubahan suhu dan kelembaban pada Inkubator di luar dari batas yang direkomendasikan.
Tabel 5 Pengukuran tegangan output Buzzer

\begin{tabular}{|c|c|c|}
\hline $\begin{array}{c}\text { Logika } \\
\text { Port }\end{array}$ & Buzzer & Keterangan \\
\hline 0 & Mati & $\begin{array}{c}\text { Suhu Normal }\left(32^{0}{ }^{-}\right. \\
\left.37^{0}\right)\end{array}$ \\
\hline 1 & Bunyi & Suhu diluar range \\
\hline
\end{tabular}

\section{Kesimpulan}

Berdasarkan hasil perancangan dan pengujian sistem, dapat dapat disimpulkan:

1. Sistem ini mampu menjaga suhu dalam Inkubator pada interval $32^{\circ}$ $35,5^{\circ} \mathrm{C}$ dan kelembaban antara 50$80 \%$. Berarti rekomendasi medis dapat terpenuhi.

2. Alarm yang ada pada sistem ini dapat membantu petugas klinik/perawat untuk mengetahui adanya kesalahan dari sistem.

\section{DAFTAR PUSTAKA}

Budiharto,Widodo. 2011. Elektronika Digital dan Mikroprosesor. Yogyakarta:Andi Offset

Cooper, William D. 1993. "Instrumentasi Elektronik dan Teknik Pengukuran". Jakarta: Erlangga

Iswanto.ST.2008."Design dan Implemendasi Sistem Embedded Mikrokontroller ATMega8535 Dengan Bahasa Basic". Yogyakarta: Gava Media 
ISSN : 2407-0491

\section{Jurnal Edik Informatika}

E-ISSN : 2541-3716

Penelitian Bidang Komputer Sains dan Pendidikan Informatika

V2.i1(123-130)

Malvino, Albert Paul. 2005. "Prinsip-Prinsip Elektronika”. Jakarta: Erlangga.

Rangkuti, Syahban. 2011. "Mikrokontroler Atmel AVR”. Bandung: Informatika
Setiawan, Iwan. 2009. "Buku Ajar Sensor dan Transducer”. Semarang: Universitas Diponegoro Press

Setiawan, Afrie. 2010. "Aplikasi Mikrokontroller Atmega 8535 Menggunakan Bascom AVR”. Yogyakarta: Andi Offset 